goal of having a multi-language Periodic Table Challenge to better reach IUPAC global communities. Beside Arabic, the multi-language pilot now also offers the PT Challenge in Chinese and in Spanish. For the Chinese version, the translation has being provided by the Chinese Chemical Society (Lidong Han, et. al.) and for the Spanish version, the translation was prepared by Sergio Menargues and Javier García-Martínez.

Prof. Christopher Brett, IUPAC president said "It is very encouraging to see the huge enthusiasm and interest that has been generated worldwide by the PT Challenge and will certainly be enhanced by its being available in other languages."

If you have an interest in supporting an effort to have a language that is important to your involvement in the Periodic Table Challenge, made available to the global science and chemistry community, please contact Dr. Lynn Soby <executivedirector@iupac.org>.

https://www.iupac.org/periodic-table-challenge

\section{Emeritus Fellows}

tarting in 2020, IUPAC has established across all Divisions a new category of membershipEmeritus Fellow-that is to be bestowed upon meritorious individuals who have earned by service a special recognition upon their retirement from one or more Division administrative positions or from a multiple of key Division Project roles.

Emeritus Fellows retain a standing invitation to attend Division and Subcommittee Meetings appropriate to their interest and technical background and are kept abreast of Division activities. Fellows are encouraged to remain active with the Divisions as ad hoc consultants and can still hold future IUPAC position and participate in future IUPAC Projects. The Chemistry and Human Health Division (Div VII) has had such a EF program since 2010 .

Thus far the 2020 class of Emeritus Fellows includes:

\section{Polymer Division (Div IV)}

Prof. Michael Buback (Germany) - Member since 1997; Division President in 2012-2015

Prof. Jung-II Jin (Korea) - Member since 1991; Division President in 2006-2007 and IUPAC President in 2008-2009

Prof. Richard (Dick) G. Jones (UK) - Member since 1997
Prof. Pavel Kratochvíl (Czech Republic) - Member since 1979 (See also p. 48)

\section{Chemistry and the Environment (Div VI)}

Dr. Laura L. McConnell (US) - Member since 2004; Division President in 2012-2015

\section{Chemistry and Human Health (Div VII)}

Prof. Michael Schwenk (Germany) - Member since 2004; Division Secretary from 2010 to 2016; currently corresponding member with the Interdivisional Standing Committee on Green chemistry for Sustainable Development.

Chemical Nomenclature and Structure Representation (Div VIII)

Prof. G. Jeffery Leigh (UK) - Member since the late 60 s starting in the Inorganic Chemistry Division (Div II); Div II President in 1996-1997. Member on Div VIII starting its creation inception in 2002.

Dr. Alan McNaught (UK) - Member since the later 70s, starting on the Commission on Nomenclature of Organic Chemistry; later member on the Division of Organic Chemistry (Div III) and on the IUBMB-IUPAC Joint Commission on Biochemical Nomenclature. In the 90s, members and Secretary on the Interdivisional Committee on Nomenclature and Symbols (IDCNS), and also member on the Committee of Printed and Electronic Publications. First Div VIII President from 2002 to 2005.

Dr. Warren Powell (USA) - Member since the mid 60s, first in the subcommittee on carotenoid nomenclature. Later member and secretary (for 10 years) of the Commission on Nomenclature of Organic Chemistry, member of Div III and of IDCNS. First Secretary of Div VIII from 2002 to 2007.

The selection and appointment are coordinated by each Division. Biographical curricula vitae of each fellows are available online.

https://iupac.org/who-we-are/emeritus-fellows/

\section{$\mathrm{Cl}$ Green is back, online}

For about 24 years, from 1979 to 2003, Chemistry Internationa/ was print only and easily recognizable with its glossy green cover. It was so green that it stained the readers fingers! Today, the early volumes of $\mathrm{Cl}$ are freely available online, and without stains. 